\title{
Study of pulmonary function test in hypothyroidism
}

\author{
Bemat Ilyas Yaqub ${ }^{1}$, Mohammed Suhail,"*, Amarnath Baswantrao Solepure ${ }^{3}$, Badar Azhar Daimi ${ }^{4}$, \\ Bemat Ishrat Fatima ${ }^{5}$
}

\begin{abstract}
1,2,5 Assistant Professor, ${ }^{3}$ Professor and Dean, ${ }^{4}$ Associate Professor, ${ }^{1-4}$ Dept. of Physiology, ${ }^{5}$ Dept. of Obstetrics and Gynaecology, Indian Institute of Medical Science and Research, Warudi, Badnapur, Jalna, Maharashtra, India
\end{abstract}

*Corresponding Author:

Email: drmohammedsuhail@gmail.com

Received: $17^{\text {th }}$ July, 2018

Accepted: $20^{\text {nd }}$ July, 2018

\begin{abstract}
Introduction: Thyroid disorders are very common worldwide and there is steep rise in thyroid disorders in India as well. ${ }^{1}$ There are very few studies done in past to evaluate effect of thyroid disorder on pulmonary function. This study is focused on estimating effects of hypothyroidism on pulmonary function of affected individual.

Aim: To study pulmonary function test in hypothyroid patients and to assess correlation of compromised pulmonary function with Thyroid stimulating hormone levels, duration of hypothyroidism, age of patient and body mass index values.

Materials and Methods: A total of 67 hypothyroid patients were selected. This study was approved by the Ethical Committee. The present study was carried out in accordance with the Helsinki declaration all participants participated voluntarily after being given a detailed explanation of the purpose of the study. All hypothyroid patients visiting medicine OPD and those hospitalised were included in study. Smokers, former smokers, patients suffering from lifestyle disease and all patients suffering from pulmonary diseases were excluded from study. Pulmonary function tests were evaluated by computerised spirometer HELIOS 702 of recorders and medicare systems private limited (RMS). Data so obtained was analysed with the help of SPSS.

Results: both FVC and FEV1 means were decreased. 44\% of patients were having restrictive type of lung disease. Forced vital capacity (FVC) and forced expiratory volume in one sec (FEV1) showed strong negative correlation with Thyroid stimulating hormone levels (TSH), duration of hypothyroidism and Body mass Index (BMI).

Conclusion: Findings of this study were consistent with restrictive type of lung disease in hypothyroid patients. Hypothyroidism compromises the pulmonary function of affected individual to variable degree depending upon duration of disease and higher levels of TSH and BMI. All hypothyroid patients must be screened for abnormalities of pulmonary function and all patients with impaired pulmonary function must be screened for thyroid function test to detect and prevent adverse outcomes.
\end{abstract}

Keywords: Hypothyroidism, Forced vital capacity, Pulmonary function test, TSH, BMI, Duration of disease.

\section{Introduction}

Thyroid disorders are very common worldwide and there is steep rise in thyroid disorders in India as well. According to prevalence studies done in various cities in India projected burden of patient suffering from thyroid disorders is 42 million. ${ }^{1}$ According to study done by AG Unnikrishnan nationwide prevalence of disease is $10.95 \%$, out of that $3.47 \%$ were unaware of the disease condition they had and were diagnosed for the first time. Altered Thyroid function specially hypothyroidism is very common and affects almost all the systems of body causing decrease in BMR, heat intolerance thinning of hair, impairment of memory. ${ }^{2}$ One of the complications of hypothyroidism is impaired pulmonary function. ${ }^{3}$ There are very few studies done in past to evaluate effect of thyroid disorder on pulmonary function. This study is focused on estimating effects of hypothyroidism on pulmonary function of affected individual.

\section{Materials and Methods}

After receiving permission from ethics committee this study was done at JIIUs Indian Institute of Medical Science and Research and Noor hospital Wardui Jalna over 6 months. 67 hypothyroid patients visiting medicine OPD and those hospitalised were included in the study. Smokers, former smokers, patients suffering from lifestyle diseases and all patients suffering from pulmonary diseases were excluded from study. The present study was carried out in accordance with the Helsinki declaration all participants participated voluntarily after being given a detailed explanation of the purpose of the study. Diagnosis of hypothyroidism was done by obtaining retrospective records of thyroid function test. Thyroid function test was done by obtaining fasting venous blood sample from antecubital vein. Pulmonary function tests were evaluated by computerised spirometer HELIOS 702 of recorders and medicare systems private limited (RMS) at department of physiology. Values of FVC (forced vital capacity), forced expiratory volume in one second (FEV1) and ratio of FEV1 to FVC were estimated. Data so obtained was entered into Microsoft office excels and analysed with the help of SPSS.

\section{Results}

Table 1 shows demographic profile of hypothyroid patients. Out of 67 hypothyroid patients $44 \%$ patients had restrictive type of lung disease and rest $66 \%$ patient had normal pulmonary function test. Table 2 shows 
means and standard deviations of pulmonary function test parameters. Percentage predicted value of FVC, FEV1 and FEV1/FVC were $59.69 \pm 10.24,62.35 \pm$ 6.061 and $78.94 \pm 14.8$ respectively. It is evident from these values that all three parameters i.e. FVC, FEV1 and FEV1/FVC are decreased in study population. FVC value is decreased more than FEV1 and ratio of FEV1 to FVC is relatively high. On analysing each report individually 30 patients out of 67 patients were having restrictive type of lung disease as their FVC was less than $70 \%$ and FEV1 values were more than $80 \%$ and FEV1/FVC ratio were normal to high.

Table 1: Demographic characteristic

\begin{tabular}{|l|c|}
\hline & Study group \\
\hline Parameters & Mean + SD \\
\hline Age & $42.07 \pm 8.5$ \\
\hline Height & $161 \pm 2.9$ \\
\hline Weight & $65.73 \pm 14.06$ \\
\hline BMI & $25.1 \pm 5.46$ \\
\hline TSH & $21.611 \pm 10.13$ \\
\hline
\end{tabular}

Table 2: Spirometry parameters study population

\begin{tabular}{|l|c|c|c|c|}
\hline & Predicted & Measured & \% predicted & p-value \\
\hline FVC & $2.39 \pm 0.3135$ & $1.92 \pm 0.4021$ & $59.69 \pm 10.24$ & $<0.001$ \\
\hline FEV1 & $2.0683 \pm 0.28$ & $1.7281 \pm 0.2511$ & $62.3595 \pm 6.061$ & $<0.001$ \\
\hline FEV1/FVC \% & $64.235 \pm 0.65$ & $68.09 \pm 12.67$ & $78.94 \pm 14.8$ & 0.0141 \\
\hline
\end{tabular}

Table 3: Correlation between different study parameters

\begin{tabular}{|l|c|c|c|}
\hline & FVC test & FEV1 TEST & FEV1/FVC test \\
\hline \multirow{2}{*}{ TSH } & $\mathrm{r}=-0.879$ & $\mathrm{r}=-0.364$ & $\mathrm{r}=0.743$ \\
& $\mathrm{p}=0.000$ & $\mathrm{p}=0.002$ & $\mathrm{P}=0.000$ \\
\hline \multirow{2}{*}{ Duration } & $\mathrm{r}=-0.605$ & $\mathrm{r}=-0.107$ & $\mathrm{r}=0.609$ \\
& $\mathrm{P}=0.000$ & $\mathrm{P}=0.389$ & $\mathrm{P}=0.000$ \\
\hline \multirow{2}{*}{ BMI } & $\mathrm{r}=-0.829$ & $\mathrm{r}=-0.455$ & $\mathrm{r}=0.615$ \\
& $\mathrm{P}=0.000$ & $\mathrm{P}=0.000$ & $\mathrm{P}=0.000$ \\
\hline \multirow{2}{*}{ Age } & $\mathrm{r}=-0.107$ & $\mathrm{r}=-0.038$ & $\mathrm{r}=0.091$ \\
& $\mathrm{P}=0.390$ & $\mathrm{P}=0.760$ & $\mathrm{P}=0.463$ \\
\hline
\end{tabular}

Table 3 shows correlation between different study parameters. There is strong negative correlation between TSH value and Forced vital capacity ( $\mathrm{r}=-$ $0.879, \mathrm{P}<0.001$ ) with increase in TSH levels there is decrease in FVC. There is negative correlation between TSH levels and FEV1 values in study population, compared to FVC the correlation between FEV1 and $\mathrm{TSH}$ is of lower degree. There is fall in FEV1 levels with increase in TSH but fall is less than fall in FVC value. Similarly there is strong negative correlation between BMI, FVC and FEV1 value in study population as BMI rises there is fall in value of FVC and FEV1 $(r=-0.829 \quad \mathrm{P}<0.001) \&(\mathrm{r}=-0.107 \quad \mathrm{P}=0.389)$ respectively. Negative correlation is found between age, FVC and FEV1 value but it is statistically insignificant.

\section{Discussion}

Thyroid hormones plays crucial role in almost all bodily functions, specially maintenance of body mass index. Thyroid hormones do play an important role in maintenance of normal respiratory function by regulating respiratory drive and keeping compliance of pulmonary interstitial tissue normal. Hypothyroidism is characterised by decrease in levothyroxine levels and rise in TSH levels. As TSH levels are single most important test for evaluation of thyroid function. Present study showed following results.
1. Higher levels of TSH are associated with lower values of FVC and FEV1 but value of FVC is compromised more than FEV1 these findings are consistent with study done by Sadek SH et al. ${ }^{4}$

2. Longer duration of hypothyroidism is associated with compromised pulmonary function specially FVC.

3. Obesity reflected from higher BMI value are associated with impaired pulmonary function as there is fall in FVC and FEV1 values.

4. Individual analysis of pulmonary function reveals $30 \%$ of patients were suffering from restrictive type of lung disease, this is in contradiction to Iyer SK et $\mathrm{al}^{5}$ and Bhuvaneswari $\mathrm{T}$ et $\mathrm{al}^{6}$ Findings are consistent with study done by Roel $\mathrm{S}$ et $\mathrm{al}^{7}$ and Sharifi F et al. ${ }^{8}$

Hypothyroidism causes decreased respiratory drive leading to pulmonary hypoventilation. ${ }^{9}$ Hypothyroidism also leads to myopathy of respiratory muscle ${ }^{10}$ and deposition of muscopolysaccharides in pulmonary interstitium and decreased pulmonary compliance. ${ }^{11,12}$ all these changes lead to restrictive type of lung disease in hypothyroid patients. In present study emphasis is also given to individual analysis of spirometry parameters of each patient along with analysis of spirometry parameter means. Very few studies in past have given prevalence of restrictive lung disease in study population along with correlation of spriometry 
parameters with TSH, duration of disease, BMI and age of patient. Present study is unique in statistically analysing these parameters. Limitation of this study is limited sample size as study is done in rural Maharashtra. Studies with larger sample size are urgently needed to detect compromised pulmonary function in hypothyroid patients of this region.

\section{Conclusion}

Hypothyroidism leads to impaired pulmonary function. Higher TSH levels, longer duration of disease and high BMI leads to greater fall in spirometry parameters specially forced vital capacity. So all the patient suffering from hypothyroidism must be screened for impaired pulmonary function test and all patient with compromised pulmonary function should be screened for presence of hypothyroidism to prevent adverse outcomes.

\section{Conflict of Interest: Nil}

\section{Acknowledgment: Nil}

\section{References}

1. Unnikrishnan, Ambika Gopalakrishnan et al. "Prevalence of Hypothyroidism in Adults: An Epidemiological Study in Eight Cities of India." Indian Journal of Endocrinology and Metabolism 17.4 (2013):647652. PMC. Web. 16 July 2018.

2. Ge JF, Peng L, Hu CM, Wu TN. Impaired learning and memory performance in a subclinical hypothyroidism rat model induced by hemi-thyroid electrocauterisation. $J$ Neuroendocrinol. 2012 Jun;24(6):953-61.

3. Ali Eman R Assessment of functional lung impairment in patients with thyroid disorders. Egyptian Journal of Bronchology. 2016;10(3):337-347.
4. Sadek SH, Khalifa WA, Azoz AM. Pulmonary consequences of hypothyroidism. Annals of Thoracic Medicine. 2017;12(3):204-208. doi:10.4103/atm.ATM_364_16.

5. Iyer SK, Menon SK, Bahuleyan B. An Analysis of Dynamic Pulmonary Functions of Hypothyroid Patients. Journal of Clinical and Diagnostic Research: JCDR. 2017;11(3):CC10-CC12. doi:10.7860/JCDR/2017/24653.9579

6. Bhuvaneswari T, Banu KK. Evaluation of pulmonary functions in patients with hypothyroidism who are on conservative management. Sch J App Med Sci. 2014;2(2A):495-97.

7. Roel S, Punyabati O, Prasad L, Salam R, Ningshen K, Shimray AJ, et al. Assessment of functional lung impairment in hypothyroidism. IOSR J Dent Med Sci. 2014;13:4-7.

8. Sharifi F, Amari A. The effect of levothyroxine on pulmonary function tests of hypothyroid patients. Int $J$ Endocrinol Metab. 2005;3(1):48-51.

9. Bassi R, Dhillon SK, Sharma S, Sharma A, Tapdiya M. Effect of thyroid hormone replacement on respiratory functions tests in hypothyroid women. Pak J Physiol. 2012;8(2):20-3.

10. Khaleeli AA, Griffith DG, Edwards RH. The clinical presentation of hypothyroid myopathy. Clin Endocrinol (Oxf) 1983;19:365.

11. Husain AN, Kumar V. Robbins and Katran Pathologic Basis of Disease. 7th ed. Philadelphia: The W.B. Saunders Company; 1999. The lung. pp. 711-72.

12. van Tuyl M, Blommaart PE, de Boer PA, Wert SE, Ruijter JM, Islam S, et al. Prenatal exposure to thyroid hormone is necessary for normal postnatal development of murine heart and lungs. Dev Biol. 2004;272(1):104-17.

How to cite this article: Yaqub BI, Suhail M, Solepure AB, Daimi BA, Fatima BI. Study of pulmonary function test in hypothyroidism. Ind $\mathrm{J}$ Clin Anat Physiol. 2018;5(3):394-396. 